\title{
Study on the Translation of News Reports
}

\author{
Wang Zheng \\ Tan Kah Kee College, Xiamen University
}

Keywords: News; Translation; Texts

\begin{abstract}
Ever since we entered the age of information globalization, we have witnessed incredible changes brought about by the rapid development of news media. News reports play an even more important role in this era of mass media. It is against this background that the author of this thesis explores the nature and characteristics of news texts. In addition, a large number of sample translations of different types of news reports have been collected as data for discussions of the features and characteristics of typical news texts. Finally, this paper introduces two useful translation strategies of domestication approach and local adaptation, which better helps readers to understand the nature and characteristics of news media English and sheds light on further studies of news English and its application to more varieties of translation studies.
\end{abstract}

\section{Introduction}

\subsection{Definition of News.}

News is information about current events. This may be provided through many different media: word of mouth, printing, postal systems, broadcasting and electronic communication. Common topics for news reports include war, government, politics, education, health, the environment, economy, business, fashion, and entertainment, as well as athletic events, quirky or unusual events.

\subsection{Writing Style of News.}

News style encompasses not only vocabulary and sentence structure, but also the way in which stories present the information in terms of relative importance, tone, and intended audience. The tense used for news style articles is past tense.

News writing attempts to answer all the basic questions about any particular event—who, what, when, where and why (the Five Ws) and also often how-at the opening of the article. This form of structure is sometimes called the "inverted pyramid", to refer to the decreasing importance of information in subsequent paragraphs. News reports generally adhere to an expository writing style. They offer anecdotes, examples and metaphors, and they rarely depend on generalizations or abstract ideas (Wilson, 1993).

\section{The Translation of News}

News belongs to the informative and expository text type. The most important point is to inform the reader about the facts that take place in the world. News translation is different from literature translation. The language in literary works is intended to create images of arts, while the language of news focuses on conveying facts.

News reports are usually explicit and precise and try not to rely on jargon. As a rule, translators of news reports will not use a long word when a short one will do. They use subject-verb-object construction and vivid, active expression

The task of news requires that its language should be accurate, brief and vivid. The essence of news language is fact-conveying and no personal feelings should be added to it. As part of mass media, news language is also "receivers' language”. It should be popular and easily understood by most people. Therefore, the translated news should also follow the above-mentioned principles of news language. At the same time, since it is translation, it differs from the SL news in one way or another. 


\subsection{Lexical Feature.}

Pay Attention to Translation of Neologism. Jargons and Neologisms make frequent appearances in news coverage. With the emergence of new things in large numbers, neologisms in news reports have been increasing speedily.

Except that news content itself should be "new", linguistically journalistic lexis plays an important part in embodying novelty of news. Neologisms are newly coined words or words that are given new meaning to fit new situations because of social, economic, political, cultural, scientific and technical changes in human society.

Hence, how to catch precisely the connotation and denotation meaning of neologisms and translate them correctly and properly is a tough problem to be dealt with by journalistic translators. Language is the carrier of culture. Vocabulary is the most active element in the three key elements of a language. Accurate translation of these neologisms is the key of news translation. The following examples show how neologisms are perfectly translated in news language. Foreignization approach is often used to translate these neologisms.

For example:

Nobleman诺贝尔奖获得者

Skylab太空实验室

Smokeout戒烟运动

Checkbook participation支票参战，以出钱不出兵的形式参战

McCarthyism麦卡锡主义

job-hopping跳槽

drug king毒泉

soft land软着陆

\subsection{Syntax Features.}

As the two languages have totally different arrangement of news headings, so, at least two steps can be used for the conversion from English to Chinese sentences-one is division, and the other is transformation plus reordering.

\subsubsection{Division.}

ST: (1)Trying to pass another car while traveling at high speech brought (2)serious injury (3)two men (4)last night (5)when their automobile overturned twice (6)on Washington Boulevard at Potter Avenue.

After decomposing the original sentence into several meaningful groups, the transformation and reconstruction can be carried out in the meantime.

\subsubsection{Transformation plus Reordering.}

TT: (4)昨晚，(3)两名驾车男子(6)在波特大街的华盛顿大道口(2)发生车祸，严重受伤，(1)车 子在试图高速超越另一辆车时(5)连打了两个滚。

Different from the original text, the time, spot, agents and result of the event are adjusted to the front part of the Chinese version, and the reason is placed at the back. Because the linear components of a Chinese sentence are more often interconnected through internal logical relationship instead of by marked linguistic denotations (Liu Qizhong, 2004:71)

\subsubsection{Sentence Voice.}

Like other English writing, active voice takes priority. Active voice helps bring the effects of directness and straightforwardness. Active voice is considered more direct and vigorous. Even so, passive voice still has its place, and it is used more frequently in journalistic English than in other 
styles. It emphasizes on the "receiver" rather than the "doer" of the verbs.

There are many cases in which passive voice is considered better, for example:

ST: 他说，“迄今已花掉了10亿美元(约合78亿港币)其中一半用于基础设施的建设。”

TT: He said, “about Us \$ 1 billion had already been spent, half of it on infrastructure.” (Liu Qizhong, 2004:71)

ST: Journalists were barred from approaching the site.

TT: 不准记者接近那个俘虏营。(Liu Qizhong, 2004:71)

ST: He said that the issue of scrapping the peg could be considered.

TT: 他说，(港币一美元)联系汇率脱钩的问题可以加以考虑。(Liu Qizhong, 2004:71)

ST: The injured were rushed to a nearly hospital by the police.

TT: 受伤者已由警察送到了附近的一家医院。

There are some special vocabulary expressions to express passive voice. For example, when the subject of original sentence is “it”, some indefinite subjects such as “有人”, “人们”, “大家” should be added to translation.

For instance:

It was asserted that...有人断言...

It was considered that...大家认为...

It was foreseen that...根据推测...

It was well known that...众所周知...

\subsection{Tense.}

Present tense and present-progressive tense are commonly used in journalistic English, for they present an image of immediacy and freshness. News writer's job is to tell the news as though it is in progress or has just recently happened and he should make it sound as new and exciting as possible because most of the audience will be hearing the story for the first time. Use of present-tense verbs, particularly present-progressive verbs, which suggest ongoing actions, adds to that immediacy.

For example:

Poor: A hurricane warning was issued tonight for Florida and Geogia.

Good: A hurricane warning is in effect tonight for Florida and Geogia.

Generally speaking, according to grammar rules, the tense in the subordinate clauses should be consistent with that in the main clauses. Journalistic English follows the rule in common sense. But sometimes, a news story mentions events that happened at different times or reports a statement that still holds true but was made earlier, so mixed tenses are acceptable in news writing. For example:

ST: A western diplomat said people-smuggling is an international issue and we've all got to look for an international solution.”

TT: 一位西方交官说：“人口走私是个国际问题，我们应该共同寻求一个国际性的解决方 案。”(Liu Qizhong, 2004)

Here "is" is used instead of "was" which is consistent with "said" in the main clause to emphasize the relation with present action. The use of tenses here is flexible and appropriate in news text.

ST: Their only worry in Group C was Turkey, who they have played just once in their history unfriendly in 1956.... (China Daily, December 4, 2001)

TT: 在C集团中他们唯一担忧的是土耳其，在历史上仅一次于1956年....

Here "have played" is used instead of "had played" which is consistent with "was" in the main clause to emphasize the relation with present action. The use of tenses here is flexible and appropriate. 


\section{Translation Strategies-Domestication Approach and Local Adaptation}

Since the purpose of news language is to pass facts to mass receivers, the translated version does not necessarily follow the grammar and language pattern of the source text. Long sentences and odd structure harm the brevity and readability of news, and hinder the readers from getting the message passed by it. So in most cases, news translators need to use the domestication approach and rearrange the language to adapt to TL readers' reading habits.

Due to the barriers of languages and cultures, some news reports, when translated, may not be understandable to the target audience. Only when the version is adapted to the target language and local cultural standards when it is translated, can the target audience precisely grasp the information and be likely to comprehend the contents of the news. To some extent, the translator will need to adjust certain features of the source text organization in line with preferred ways of organizing text in the target language (Baker, 2000:112).

Accordingly, proper changes are allowed in the premise of "loyalty" to fulfill the intra-textual coherence. "Loyalty" itself may also require the adaptation of certain translation units in certain circumstances. Sometimes word-for-word translation regardless of language and culture differences can cause baffling and ambiguity. After all, it is impossible to take every aspect into account and make a perfect news report. Thus, the criterion is not only "loyalty", but somewhat "local adaptation”. (Chen Xiaowei,2005:118).

There are many examples in which local adaptation is considered better, for example: news of official statements of China's foreign policy and international relations. These statements are officially translated by Xinhua news agency with the criterion of "local adaptation", which leads to an emerging dialect called "Xinhua English or New China News English".

\section{ST: 相互尊重, 求同存异}

TT: adhere to the principle of mutual respect and seek common ground while shelving differences

ST: 加强同广大第三世界国家的团结与合作是我国外交政策的一个基本立足点

TT: Itisa fundamental position in China's diplomatic policy to strengthen solidarity and cooperation with the great number of Third World countries.

\section{Conclusion}

In all, news report is relatively formal, standard and with settled formats. Itisa specialized text format with several distinctive characteristics. For Chinese news readers, they usually prefer active voice to passive voice; they use more verbs than nouns; and long complicated sentences with long modifiers should be split. Only bearing these characteristics into mind can translators of news reports do their jobs efficiently. In addition, for the limited pages in the thesis, the author cannot present all the characteristics and translation strategies to news media English in details. Those who show interest in pragmatic translation studies can refer to a variety of news reports and make more translation practice to probe into more effective strategies and approaches to news translation.

\section{References}

[1] Wilson, Kenneth G. (1993). The Columbia Guide to Standard American English. New York City: Columbia University Press.

[2] Liu Qizhong. A Course in Journalism Translation [M]. Beijing: China Renmin University Press, 2004.

[3] Jia Wenbo. Applied translation functional theory [M]. Beijing: China Translation and Publishing Corporation, 2004: 26-28.

[4] Baker, Mona. In other words: a Coursebook on Translation [M]. Beijing: Foreign Language Teaching and Research Press, 2000. 